Cadernos de Pesquisa do CDHIS

\title{
A Relação entre Arte e Vida no Pensamento Anarquista do pós-Segunda Guerra
}

\section{The Relationship Between Art and Life in Post-Second War Anarchist Thought}

Cláudia Tolentino Gonçalves Felipe ${ }^{1}$

\footnotetext{
${ }^{1}$ Doutora em História pela Universidade Estadual de Campinas - UNICAMP. E-mail: claudiatolentino.ufu@gmail.com
} 
A Relação entre Arte e Vida no Pensamento Anarquista do pós-Segunda Guerra

\section{RESUMO}

O texto busca analisar a relação entre arte e vida no pensamento libertário do pós-Segunda Guerra. Partindo do pressuposto de que a arte concedia aos "artistas" (e todos, sem exceção, teriam condições de sê-lo) a possibilidade de tornar presente o horizonte de expectativas libertário, procuramos sondar o modo como os anarquistas, rompendo com os paradigmas da arte mimética da arte romântica, teorizaram a aplicabilidade da estética na construção da sensibilidade libertária.

Palavras-chave: Arte. Vida. Sensibilidade libertária.

\section{ABSTRACT}

The text analyzes the relationship between art and life in post-World War II libertarian thought. Based on the assumption that art granted "artists" (and everyone, without exception, could become an artist) the possibility of making the horizon of libertarian expectations present, we seek to probe the way in which anarchists, breaking with paradigms of the mimetic and romantic arts, theorized the applicability of aesthetics in the construction of libertarian sensibility.

Keywords: Art. Life. libertarian sensitivity 
Em um artigo de 1948 publicado no jornal A Plebe, o anarquista Souza Passos ressaltou a importância da estética libertária² na realização prática da utopia anarquista. ${ }^{3}$ A arte, no caso, seria um instrumento fundamental na promoção de indivíduos livres, conscientes, emancipados e capazes de estabelecer relações harmônicas uns com os outros:

Integrado o indivíduo na plenitude das suas faculdades criadoras; libertado de todos os preconceitos raciais, religiosos e sociais que $\mathrm{o}$ amesquinham porque lhe destroem a personalidade, colocado na posse de todos os recursos necessários à sua capacitação cultural, estaria, sem dúvida, à altura das mais elevadas concepções artísticas. Arte é sentimento, vibração, vida e personalidade. Se os sentimentos são livres, livres também são as vibrações na vida e na personalidade do artista. Ao contrário do que acontece em nossos dias, em que as manifestações artísticas estão sujeitas ao mercantilismo da vida social, ou sofrem as consequências do desequilíbrio económico que leva os indivíduos a subordinar os seus sentimentos aos interesses criados pelo capitalismo, imagine-se até onde chegaria a força criadora do indivíduo num ambiente em que ele não sentisse a necessidade de coibirse a si mesmo! Dentro desse conceito é que devemos julgar as manifestações artísticas, se queremos compreender a arte. E o que pretende o anarquismo é justamente dar ao indivíduo a posse de si mesmo, integrá-lo na consciência plena de todas as suas faculdades criadoras (PASSOS, 1948, p. 2).

\footnotetext{
${ }^{2}$ De acordo com André Reszler, a estética libertária pode ser definida como uma concepção de arte antiautoritária, compreendida como experiência e não como um dom ou excepcionalidade de um indivíduo. Todos os homens são considerados artistas criadores em potencial. Para Reszler, William Godwin, Pierre Joseph Proudhon, Mikhail Bakunin e Piotr Kropotkin abriram caminho para o desenvolvimento de uma estética anarquista ao apontarem para o artista latente em todos os homens e para os valores da espontaneidade, da liberdade e da imaginação no ato de criar e experenciar algo novo. Ver: RESZLER, 2005, p. 07.

${ }^{3}$ O termo utopia, como salientou Cosmio Quarta, deve ser compreendido como um processo histórico que a humanidade, no curso de sua jornada, de geração em geração, desenvolve e reelabora, para suprir suas carências, suas necessidades. Ver: QUARTA, 2006, p. 49.
} 
Como libertar a arte do "mercantilismo da vida social", dos "interesses criados pelo capitalismo"? Como incentivar a "força criadora" e "dar ao indivíduo a posse de si mesmo"? De que maneira a estética libertária poderia romper com "preconceitos raciais, religiosos e sociais" e estimular a "capacitação cultural" dos homens? Este texto tem por objeto analisar a relação entre arte e vida no pensamento libertário do pós-Segunda Guerra. Partindo do pressuposto de que a arte concedia aos "artistas" (e todos, sem exceção, teriam condições de sê-lo) a possibilidade de tornar presente o horizonte de expectativas libertário, procuramos sondar o modo como os anarquistas teorizaram a aplicabilidade da estética na construção da sensibilidade libertária.

\section{Por um microcosmo libertário}

O anarquista Herbert Read $^{4}$ afirmou que a carência de arte na vida é consequência da construção de um mundo apático, violento, sustentado com base em guerras e jogos de poder. Em um de seus textos, retomado no jornal libertário Dealbar, ele afirmou que pairava sobre o mundo uma neurose de inatividade, "cujo principal consumo de energia consiste em puxar uma alavanca ou tocar um botão (...) Essa inatividade não é apenas dos músculos e dos nervos, mas dos processos criadores que outrora exigiam a participação da mente" (READ, p. 3). Para Read, a especialização do trabalho no mundo moderno proporcionou uma lacuna no desenvolvimento humano. ${ }^{5}$ Absortos em atividades repetitivas, o homem foi, aos poucos, perdendo sua capacidade criadora, transformadora, promotora de um viver pleno e positivo.

\footnotetext{
${ }^{4}$ O inglês Herbert Read (1893-1968) foi um historiador e crítico de arte que se debruçou sobre a articulação entre educação e arte para pensar a filosofia anarquista. Read foi também autor de poesias e romances de caráter libertário.

${ }^{5}$ Essa mesma reflexão está presente na obra de Fuller sobre a nave espacial Terra. Ver: FULLER, 1998.
} 
Os gregos, embora deles nos venha a nossa filosofia da arte, não tinham palavra para designar "arte". Diziam Techne equivalente à nossa palavra "Skill" (habilidade), de origem escandinava e cuja significação primitiva implica discriminação. A raiz "ar" significa "ajustar ou juntar". Aos romanos se devem provavelmente a distinção que se estabeleceu gradualmente entre as artes e os ofícios, visto que personificavam as artes e as tinham como atividades delicadas. Não obstante, durante a Idade Média arte continuou a significar essencialmente habilidade - habilidade para fazer coisas, fosse uma cadeira, música ou poesia. As artes liberais eram ensinadas nas escolas como habilidades objetivas: Gramática, Retórica, Lógica, Aritmética, Geometria, Música e Astronomia. Hoje não falamos já em artes liberais, mas em ciências; isto é, diversas categorias de conhecimento expressas numa linguagem verificável. As artes eram uma maneira de "fazer" que implicavam habilidade; as ciências são uma maneira de "conhecer" que implicam coerência lógica. A história das palavras revela a história das idéias. Chegamos ao divórcio total entre os conceitos, primitivamente idênticos, de techne e ars. Técnica, método científico, habilidade artesanal, todos estes termos implicam competência intelectual, e são características da nossa civilização tecnológica, mas, embora agonizantes escolas de arte ainda ensinem arte como habilidade, é mais geralmente tida como atividade instintiva, exercida por uma minoria de pessoas talentosas, essencialmente por inspiração, quanto a sua origem, e pessoal quanto a sua manifestação e significação (READ, 1959, p.3).

Para Read, arte e vida são elementos inseparáveis. A primeira seria uma expressão da vida humana e, portanto, crucial para a garantia de uma sociedade harmonizada, pacificada, livre de ameaças de guerras. Para o autor, o mal do mundo tinha suas raízes no abandono da formação integral do homem. Sem uma transformação orgânica, na qual o homem pudesse voltar os olhos para si mesmo em busca de um equilíbrio físico e psíquico, seria impossível a conquista de um bem-estar futuro da humanidade. Em razão de sua visita ao Brasil no ano de 1959, para o Congresso da Associação Internacional de Críticos de 
Arte, realizado em Brasília, Herbert Read concedeu uma entrevista ao jornal anarquista Ação Direta no qual discorreu sobre a relação entre existência e essência. Para ele os anarquistas deveriam

tomar posição na estrutura da sociedade existente, tomar parte em sua atividade e nos tornarmos uma unidade funcional para dessa posição realista podermos afirmar o nosso ideal. (...). Os anarquistas deveriam acolher de braços abertos a arte moderna porque é uma arte de protesto social. O artista, como afirmou Picasso, é um ser político constantemente cônscio do que sucede no mundo. A pintura é um instrumento de luta. Da mesma forma a poesia. As minhas poesias, se quiserem, são os meus atos de anarquismo; e são muito mais eficazes que as bombas (READ, 1959, p. 3).

Read fez referência à crítica libertária direcionada à arte moderna, inscrita no movimento romântico de renovação dos valores tradicionais. Ao romper com os modelos "clássicos" de escrita amparados na Instituição Retórica, o Romantismo desvalorizou igualmente um padrão de arte imitativo. Em contrapartida, inventou critérios que permitiram valorizar a autonomia, a originalidade, a genialidade de autores capazes de projetar na sua arte o que há de inusitado e/ou individual em suas técnicas. Dito de outra forma, por meio das estéticas (Kant, Hegel etc.), dos regimes de gosto (Burke, Schiller etc.) e da produção artística expressiva e psicológica, desvalorizou-se a tradição como elemento nuclear da arte e passou-se a valorizar o que havia de singular e inovador em cada autor. ${ }^{6}$ Romper com a tradição não significa, no entanto, romper com os valores antigos, mas com as formas tradicionais de representar ou figurar esses valores: se antes o critério principal das "belas-letras" seria a imitação do cânone, das autoridades vinculadas a cada gênero artístico, com o

\footnotetext{
${ }^{6}$ KANT, 2012; sobre a estética em Hegel, ver: LICHTENSTEIN, 2004, p. 115; BURKE, 1993; SCHILLER, 2011.
} 
Romantismo é a expressão individual e seu aspecto original/genial que demarca o mérito de seu agente. ${ }^{7}$

Os anarquistas recorrentemente encararam este modelo artístico romântico com inquietação, sobretudo por sua tendência em monopolizar ou hierarquizar os homens a partir de seu desempenho excepcional, subtraindo de outros indivíduos a possibilidade de serem igualmente bem-sucedidos no que diz respeito à arte. Logo, ela deveria deixar de ser uma forma de incentivar a diferença, apostando-se na sua capacidade libertária e na sua consumação coletiva, revolucionária, transformadora. Contudo, Read postulava a necessidade de os anarquistas aproveitarem o movimento de protesto presente na arte do pós-guerra para exprimir seus ideais, o que ele chamou de "essência libertária". Mais importante do que negar o caráter individualista e carregado de valores tradicionais que perpassava a arte romântica, Read apostava na ação como a melhor arma revolucionária.

Renunciar ao sistema social estabelecido não modificará coisa alguma este sistema e somente alguns excêntricos seguirão à tebaide do nosso retiro. Ninguém se abalará por nosso quixotismo e ninguém se verá profundamente influenciado. Dirão que somos doidos e posteriormente não se ocuparão de nós. (...) Tal ponto de vista é anti-heroico. Quando no drama de Bertolt Brecht sobre Galileu, o inquisidor grita para o ilustre cientista: "- Tens as mãos manchadas", Galileu responde: "Antes manchadas que vazias". Galileu poderia manter-se fiel aos seus princípios e perecer; porém, preferiu viver porque sabia que tinha ainda uma contribuição científica a prestar (READ, 1959, p. 3).

Oferecer ao mundo atuações anarquistas por meio da arte seria, para Read, uma estratégia profícua para suscitar um desejo pelo viver anárquico: iniciativa individual e coletiva, ousadia, autonomia. Read, nesta direção, trata

\footnotetext{
${ }^{7}$ Sobre as diferenças entre as "belas-letras" e a literatura, ver: RANCIÈRE, 1995.
} 
da relação entre "ação" e "consciência": o anarquista é consciente porque é ativo, e é por meio da ação que a consciência revolucionária é constituída. Reflexões semelhantes foram encontradas nos jornais anarquistas brasileiros do pós-Segunda Guerra:

A missão do anarquista não é sonhar a sociedade futura; porém deve ser atuar o mais anarquicamente possível dentro da presente sociedade; evitar tanto quanto seja possível situações em que seja mandado ou impelido a mandar; e tratar de criar relações de mútua e voluntária cooperação entre seus companheiros (OSTERGOARD, 1963, p. 3).

Houve, especialmente nas décadas de 1950, 1960 e 1970, um forte apelo no meio libertário reforçando a importância do conhecimento. Não é por acaso que o jornal Dealbar (1967-1968) traz um sol estampado como seu emblema ao lado da seguinte chamada: “A ideia é como a gota d'água pode refletir a imensidade". A razão e o conhecimento foram evocados como elementos imprescindíveis para a construção da anarquia. O homem, apreendido pelos anarquistas como ser social, ao ser tocado pelo conhecimento libertário, se uniria a outros homens que partilhavam da mesma formação. Estando eles de acordo sobre uma mesma concepção de mundo, eles tenderiam a se associar e a se organizar em prol da efetivação prática do conhecimento adquirido.

Para Read, era ilusória a ideia de que a revolução ocorreria após um cataclisma que varreria o Estado da face da Terra, dando início à anarquia. A revolução, para ele, deveria ser processada nas atitudes mentais e emocionais dos homens. Defensor da resistência não-violenta, ${ }^{8}$ ele repudiava a guerra e apostava na educação estética como mecanismo eficaz na construção de um

\footnotetext{
8 Herbert Read declarou, na década de 1940, ser favorável à guerra em algumas circunstâncias. Todavia, nos anos 50 e 60, após seu contato com o pensamento gandhiano, ele proferiu várias declarações em favor da não violência e contra a deflagração de qualquer tipo de guerra entre os homens. Ver: ADAMS, 2015, p. 86-104.
} 
mundo harmonizado e baseado em relações de reciprocidade. A arte, desse modo, poderia estimular novas relações sociais, desafiando os modos convencionais de interação humana, propondo a ajuda mútua ${ }^{9}$ em substituição à individualização, tão comum à sociedade contemporânea. Este autor defendia a importância da arte em promover uma transformação pessoal no próprio artista. Trata-se de um processo dinâmico em que a mudança pessoal aparece como um pré-requisito para a mudança social. Read apostava na universalidade dos valores estéticos e no efeito moralizante das atividades criativas, caminho que tornaria possível a vivência da utopia anarquista.

Não é novidade a importância conferida à cultura pelos anarquistas. Desde o início do século XIX, diferentes instrumentos como os jornais alternativos, os centros de cultura, as bibliotecas sociais, os sindicatos, as escolas racionalistas e as universidades populares foram utilizadas como meios de difusão das ideias libertárias e de associação entre aqueles que partilhavam deste mesmo ideal. Como asseverou Allyson Bruno, entre a queda da ditadura Varguista e os anos iniciais da ditadura militar no Brasil, o aspecto cultural e educativo assumido pelo movimento libertário "longe está de uma estratégia de manutenção mínima do ideário em tempos de perda de inserção social", como enfatizaram estudiosos do anarquismo deste período. A importância dada a este tipo de prática acompanha a "militância anarquista em quaisquer conjunturas" (VIANA, 2014, p. 28), sejam elas perpassadas ou não pela restrição das liberdades.

Havia, no período do pós-Segunda Guerra, uma aposta por parte de vários anarquistas na arte como um mecanismo privilegiado de transgressão. Em meio aos tempos sombrios então vivenciados, apostava-se nas faculdades criadoras como mola propulsora para a construção de um mundo pacificado.

\footnotetext{
${ }^{9}$ Há em Read uma forte inspiração na teoria do "Eu-Tu" de Martin Buber, que apontava para a conexão/comunhão entre os homens na construção da anarquia. Ver: idem.
} 
Na antologia Patterns of Anarchy, publicada em 1966, os organizadores consideravam imprescindível a discussão sobre ética para se compreender a filosofia libertária. Para eles, era um fato inegável que o anarquismo do seu tempo era plural, formado por correntes distintas que investiam em diferentes modos de organização e atuação libertárias. Contudo, havia entre elas um fundo comum, pautado na negação da autoridade. Todo anarquista, diziam eles, recusava qualquer imperativo obrigatório, subvertendo quaisquer possibilidades de relações hierárquicas de poder. Nesse sentido, o anarquismo foi concebido como uma ética individualizada que permite ao homem a capacidade de analisar individualmente as circunstâncias e tomar decisões livremente, sem qualquer tipo de coerção. Segundo os autores, essa compreensão do anarquismo foi bem delineada por Kropotkin e, naquele momento, tornava-se uma reflexão cara aos libertários, pois compreender os princípios que regiam uma dada filosofia seria primordial para o aprimoramento das técnicas necessárias para sua efetivação prática. Os organizadores de Patterns of Anarchy enfatizaram a importância que alguns pensadores conferiam à educação:

o fim do ensino não é aprofundar doutrinas e padrões específicos, mas desenvolver a autonomia da criança para enfrentar qualquer problema intelectual. Os anarquistas insistem que cada indivíduo deve seguir seu próprio julgamento sem ser escravizado pelos sistemas previamente estabelecidos. Com a possível exceção do "anarquista derivado", eles rejeitam a soberania das regras morais que determinam a conduta de alguém, impondo compromissos impermeáveis às demandas de situações específicas. Nós seguimos tais regras previsivelmente, e elas realmente se tornam imperativos mentais, ideias fixas. Cada vez que obedecemos a uma máxima moral, deve haver um ato de julgamento separado, uma decisão separada de consentir com o que é prescrito. Caso contrário, tudo o que for feito se torna antiético, impessoal, inadequado (KRIMERMAN, 1966, p. 558). 
Avesso à autoridade exterior à sua própria consciência, o anarquista tem como corolário uma integração dinâmica entre meios e fins, baseada na liberdade. A educação e o ativismo social assumem um caráter especial, calcado em um processo participativo e avesso à hierarquização. Buscava-se um desenvolvimento pleno de todas as faculdades: intelectuais, artísticas e morais. O homem deveria ser capaz de avaliar as consequências morais de suas escolhas e ações. A liberdade, no caso, tem uma correlação estreita com a responsabilidade social. Sendo o homem um ser social, ele se interessaria também pelo desenvolvimento pleno de todos à sua volta. Read, em um artigo publicado nesta mesma antologia, afirmou que o desenvolvimento de qualidades e ações positivas nos homens eliminam os seus opostos. Ele defendeu que, com o desenvolvimento de uma ética anarquista, não haveria espaço para a coerção entre os homens ou para a manifestação de qualquer outro mal que pudesse corrompê-la. Em suas palavras,

a singularidade não tem valor prático isoladamente. Uma das lições mais importantes da psicologia moderna e das experiências históricas recentes é que a educação deve ser um processo não apenas de individuação, mas também de integração, que é a reconciliação da singularidade individual com a unidade social (READ, 1966, p. 407).

Nesse raciocínio, seria imprescindível que, para gerar o efeito esperado, a educação e o ativismo social assumissem a configuração da ética libertária. Krimerman e Perry (1966, p. 559), citando Gustav Landauer, afirmaram:

O estado é uma condição, um certo relacionamento entre as pessoas, um modo de comportamento; nós o destruímos quando estabelecemos diferentes relacionamentos e nos comportamos de uma maneira diferente. 
Com isso, reitera-se que, no seu ativismo, os anarquistas sempre deveriam adotar essa prescrição. Mas como poderiam fazê-lo? Read (1966, p. 408) sugeriu um caminho: seria necessário o aguçamento da sensibilidade estética dos homens. Assim, poder-se-ia construir uma relação harmoniosa entre eles. Read baseou-se na psicologia social de Erich Fromm ao defender que o bloqueio da espontaneidade, da expressão, das capacidades sensuais, emocionais e intelectuais levariam a um redirecionamento da energia do homem para a destruição de si e dos outros. A arte, compreendida como expressão da vida, seria um eficaz mecanismo de formação livre e harmônica:

Arte, como vimos, é uma disciplina que os sentidos buscam em sua percepção intuitiva da forma, da harmonia, da proporção, da integridade ou totalidade de qualquer experiência. É também a disciplina da ferramenta e do material - a disciplina imposta pelo lápis ou caneta, pelo tear ou pela roda do oleiro, pela natureza física da tinta, têxteis, madeira, pedra ou argila. Mas o ponto sobre esta disciplina é que ela é inata: faz parte de nossa constituição fisiológica e existe para ser encorajada e amadurecida. Não precisa ser imposta pelo diretor da escola ou pelo sargento: não é uma espécie de tortura física. É uma faculdade dentro da criança que responde à simpatia e ao amor, à antecipação inteligente de impulsos e tendências na individualidade da criança. Por esse motivo, o professor deve ser primariamente uma pessoa e não um pedagogo, um amigo, e não um mestre ou amante, um colaborador infinitamente paciente... A arte das crianças é extremamente importante por esse mesmo motivo: é a mais antiga e o mais exato índice da psicologia individual da criança. Uma vez conhecida a tendência psicológica de uma criança, sua própria individualidade pode ser desenvolvida pela disciplina da arte, até que ela tenha sua própria forma e beleza, que é sua contribuição única para as belezas da natureza humana (READ, 1966, p. 411-412).

O mesmo deveria ser feito no ativismo social. Read atentou-se para a importância de se oferecer ao mundo expressões artísticas carregadas da ética 
libertária. Trata-se não apenas da criação de poemas, canções, utopias ou apresentações teatrais, mas também da difusão de um modo de vida libertário por meio da expressão artística. A arte e a vida seriam, pois, indissociáveis, como é possível constatar na declaração abaixo, do anarquista Jackson Mac Low: ${ }^{10}$

Um anarquista não acredita, como alguns colocaram erroneamente, no caos social. Ele acredita em um estado da sociedade em que não existe uma estrutura de poder congelada, onde todas as pessoas podem fazer escolhas iniciais significativas em relação à matéria que afeta suas próprias vidas. (...) Qual a melhor forma de incorporar essas idéias no microcosmo do que criar obras nas quais outros seres humanos e seus ambientes e o mundo "em geral" sejam capazes de agir dentro da estrutura geral e de 'regras' dadas pelo poeta "o criador de enredos ou fábulas"? Como insiste Aristóteles - o poeta é preeminentemente o criador do enredo, do arcabouço não necessariamente de tudo o que acontece nesse quadro! $\mathrm{O}$ poeta cria uma situação em que ele convida outras pessoas e o mundo em geral a serem co-criadores com ele! Ele não deseja ser um ditador, mas um co-iniciador leal de ações dentro da sociedade livre de iguais, que são esperanças de que seu trabalho ajude a promover. Que a arte em si consiga levar a novas descobertas sobre a natureza do mundo e do homem, não tenho dúvida (...). Além disso, situações absolutamente únicas podem surgir durante a execução de tais obras, e as experiências daqueles que participam delas (sejam como artistas, público ou ambos) não podem deixar de ter novos significados estéticos (experienciais). Ou seja, não apenas as obras incorporam e expressam certos significados metafísicos,

10 Jackson Mac Low foi um poeta, artista performático, compositor e dramaturgo americano. É conhecido no meio libertário pelo seu ativismo pacifista contra a guerra e a violência. Foi aluno de Composição Musical Experimental de John Cage na New School for Social Research. Em 1963 ele compôs uma obra performática intitulada "3 projetos sociais" no qual convida o leitor a encontrar uma maneira de acabar com o desemprego, com as guerras e de promover a produção e distribuição de tudo que os homens precisam para viver. Mac Low foi um dos fundadores do projeto Fluxus e teve participação ativa em apresentações performáticas e teatrais no The Living Theatre dos anarquistas Julian Beck e Judith Malina. Ver: LAYMAN, 1998, p. 193-202. 
éticos e políticos, mas também trazem à existência novos significados estéticos (LEARY; KELLY, 1965, p. 540).

Mac Low trabalhava com o acaso e com a indeterminação. O lançamento de dados ou de uma moeda podia determinar a duração ou natureza de um som ou a estrutura de uma peça. Quando este artista organizava um conjunto de palavras que deveriam ser faladas ao acaso, o compositor não determinava ou controlava a sequência a ser seguida pelo leitor. Tratava-se de uma interação da linguagem com a indeterminação da vida. Melhor dizendo, tratava-se de ações pragmáticas que permaneciam afastadas do tradicional determinismo e cientificismo da arte moderna.

Ao debruçar-se sobre o legado libertário da arte de Mac Low, Danielle Spinosa ponderou que o caráter anarquista de sua obra estaria presente não apenas na adoção do método de escrita aleatório e não intencional, mas, sobretudo, no papel que o leitor adquiriu ao entrar em contato com sua obra, tornando-se partícipe e intérprete dos significados ali presentes. Importante salientar que Mac Low produzia textos assintáticos partindo de uma compreensão específica sobre o significado intrínseco de todos os sons. Para ele, existia algo significativo em qualquer som emitido por um ser senciente (capaz de ter percepções sensitivas e conscientes do que lhe acontece e do que o rodeia):

Acredito (apesar de Saussure e seus seguidores) que há uma conexão intrínseca entre som e significado. No entanto, cada palavra tem vários significados diferentes relacionados a ele, e esses múltiplos significados podem ser combinados em um número infinitamente grande de maneiras, de modo que, os que percebem um trabalho como o meu podem encontrar (ou "encenar") para si mesmos muitos significados diferentes (MAC LOW, 2004, p. 257). 
Longe de entender a materialidade da linguagem como algo essencialmente sem sentido, Mac Low compreendia que cada fonema, intencional ou não, era um veículo para significados infinitos. De acordo com Spinosa, na poesia, por exemplo, isso colocava a responsabilidade de produção não no poeta que a compôs, mas no leitor que realizava o processo de recriação de significado no nível da experiência e da percepção. Este processo liberaria a linguagem do peso da decodificação, concedendo ao observador ou ao leitor o poder para se envolver com a obra. Para Mac Low, as palavras e unidades linguísticas não deveriam ser carregadas do "fardo" dos pensamentos, sentimentos e interesses do autor. A expressão de um autor, como afirmou Spinosa, foi recusada em favor de um envolvimento mais produtivo do leitor/observador com o texto. Libertando a linguagem da sintaxe normativa convencional, Mac Low pluralizou os processos de exegeses, de construção de significados para os leitores: cada pessoa que entrasse em contato com sua obra produziria algo novo. Trata-se, segundo Spinosa, de uma atitude que se assemelha às práticas de uma comunidade livre, na qual não haveria o exercício de nenhuma autoridade sobre o indivíduo, que permaneceria livre para promover a produção de significados. Mac Low explicou a situação em uma entrevista de 1983:

Embora os artistas não sejam diretamente regulados por uma autoridade central, eventualmente são, pois eu, como compositor, estou dando, fornecendo os materiais, procedimentos, regras, etc. É por isso que eu costumo dizer, hoje em dia, que tais performances são "analogias" em vez de "paradigmas" de comunidades livres. Assim eles estão exercendo sua própria iniciativa dentro de uma determinada situação, os materiais artísticos são analogias das condições da vida real oferecido pela natureza e pela sociedade. Em tais situações, as pessoas podem ser reguladas pelas autoridades centrais, como na maior parte do mundo moderno, ou por sua própria espontaneidade e iniciativa (MAC LOW, 1983, p. 21). 
Cláudia Tolentino Gonçalves Felipe p. $402-420$
A Relação entre Arte e Vida no Pensamento Anarquista do pós-Segunda Guerra

Reflexão semelhante foi realizada pelo anarquista John Cage ${ }^{11} \mathrm{em}$ uma entrevista concedida a Joan Retallack:

JC [John Cage]: Você iria a um show e ouviria essas pessoas tocando sem um condutor, hum? E você veria esse grupo de indivíduos e se perguntaria como diabos eles conseguem ficar juntos? E então você gradualmente perceberia que eles estavam realmente juntos, e não por causa da música feita para ficarem juntos. Em outras palavras, eles não estavam fazendo um dois três quatro, um dois três quatro, hum? Mas que todas as coisas que eles estavam soando estavam juntas e que cada uma delas vinha de cada uma separadamente, e não estavam seguindo um condutor, nem seguiam uma métrica acordada. Nem estavam seguindo um acordo. . . posso dizer poesia? - significando um sentimento bem diferente ao mesmo tempo em que estavam juntos.

JR [Joan Retallack]: Então esse é realmente um tipo de microcosmo de...

JC: De uma sociedade anarquista, sim. Que eles não teriam ideia comum, eles não seguiriam nenhuma lei comum. A única coisa que eles concordariam seria com algo que todos concordassem. . . e isto é, que horas são (CAGE; RETALLACK, 1996, p. 50-51).

Para Mac Low, assim como para Cage, a arte deveria permitir ao leitor/observador e ao próprio artista a experimentação de um microcosmo libertário. A experiência poética e musical tornaria possível a promoção de

11 John Cage foi um compositor, teórico musical, artista e escritor americano cujas composições tiveram um grande impacto no desenvolvimento da música minimalista, eletrônica e da arte performática. É considerado uma figura chave da vanguarda artística americana do pós-guerra. De acordo com Rodrigues \& Simões, Cage se aproximou dos anarquismos na década de 1940, durante sua atuação na Black Mountain College, escola de artes situada em Ashville, Carolina do Norte. Nesse momento, aproximou-se de Buckminster Fuller e de figuras do anarquismo americano como Julian Beck e Judith Malina, fundadores do The Living Theatre. Em 1954, ele se mudou para uma comunidade de artistas e intelectuais com feições libertária localizada em Stony Point, em New York, onde conheceu o anarquista James Martin. No final da década de 1960, Cage esteve no Brasil e realizou uma palestra para os anarquistas no Centro de Estudos Professor José Oiticica. Ver: RODRIGUES; SIMÕES, 2016, p. 145-153. 
comunidades libertárias nas quais artistas e partícipes experenciam um ato criador conjunto sem a interferência de nenhum tipo de autoridade. Trata-se de concretizações momentâneas da utopia anarquista, do éthos e da sensibilidade libertária.

Diferentemente da arte antiga e moderna, ora direcionada aos clássicos e à necessidade de imitá-los, ora às expressões estéticas originais e/ou geniais capazes de gerar certos efeitos em seu público, os anarquistas propunham a valorização de todos os sujeitos como agentes criadores. Concebiam a arte como um produto social, como resultado de um processo capaz de suscitar nos envolvidos experiências diversas. Longe de considerar o artista um gênio ou um ser excepcional, eles defendiam que todos os homens poderiam compreender e fazer arte - compreendida como uma modalidade de ação direta e, portanto, baseada na espontaneidade, na decisão livre dos indivíduos. A arte, adquire nesta concepção, um caráter educativo ao permitir a experimentação de novas percepções e sensibilidades, despertando nos envolvidos a autonomia, a confiança, uma melhor compreensão de si, além do espírito da cooperação. Ela não possui um fim em si mesma, pois trata-se de um mecanismo de libertação e, como tal, deveria ser praticada tendo sempre a liberdade como sua diretriz.

\section{Referências bibliográficas:}

ADAMS, Matthew. Memory, History, and Homesteading: George Woodcock, Herbert Read and Intellectual Networks. Anarchist Studies, 23:1 (2015), p. 86104.

BURKE, Edmund. Uma investigação filosófica sobre a origem de nossas ideias do sublime e do belo. Campinas, SP: Editora da Universidade de Campinas, 1993. 
CAGE, John; RETALLACK Joan. Musicage: Cage Muses on Words, Art, Music; John Cage in Conversation with Joan Retallack. Hanover: University Press of New England, 1996.

DEALBAR. São Paulo, 1967-1968.

FULLER, Buckminster. Manual de Instruções para a nave espacial Terra. Porto: Via Óptica, 2º ed., 1998.

KANT, Immanuel. Observações sobre o Sentimento do Belo e do Sublime. Seguido de Ensaio sobre as Doenças da Cabeça. Lisboa: Edições 70, 2012.

KRIMERMAN, Leonard; PERRY, Lewis. Anarchism: the method of Individualization. In: Patterns of Anarchy: a Collection of Writing on the anarchist tradition. New York: Archor Books, 1966.

LAYMAN Bruccoli Clark. Dictionary of Literary Biography. American Poets Since World War II, Sixth Series. New York, The Gale Group, 1998. p. 193-202.

LEARY, Paris; KELLY, Robert. A Controversy of Poets: an Anthology of Contemporary American poetry. New York: Archor Books, 1965.

LICHTENSTEIN, Jacqueline. A pintura - v. 5. Textos Essenciais: da Imitação à Expressão. São Paulo: Editora 34, 2004.

MAC LOW, Jackson. Interview with Nicholas Zurbrugg. In: ZURBRUGG Nicholas. Art, Performance, Media: 31 Interviews. Minneapolis: University of Minnesota Press, 2004.

MAC LOW. Jackson. In: OTT, Gil. Paper Air 2.3. San Diego: Singing Horse Press, 1983.

OSTERGOARD. Geaffrey. Programa do anarquismo: estabelecer novas relações entre os homens. O Libertário, ano III, n. 18-19, abril-mai./1963.

PASSOS, Souza. O anarquismo como expressão artística. A Plebe, São Paulo, ano XXXII, n. 17, 1948.

QUARTA, Cosmio. Utopia: gênese de uma palavra-chave. MORUS - utopia e renascimento, n. 3, 2006, p. 49. 
RANCIÈRE, J. Políticas da escrita. Tradução de Raquel Ramalhete. Rio de Janeiro: Ed. 34, 1995.

READ, Herbert. Art as the Basis of Libertarian Education. In: Patterns of Anarchy: a Collection of Writing on the anarchist tradition. New York: Archor Books, 1966.

READ, Herbert. Intelectuais no anarquismo - Entrevista com o escritor e sociólogo Herbert Read. Ação Direta, Rio de Janeiro, ano XIV, n. 136, 1959.

RESZLER. André. La estética anarquista. Buenos Aires: Libros de la Araucaria, 2005.

RODRIGUES, Thiago \& SIMÕES, Gustavo. Para além do concerto: uma nota sobre a anarquia de John Cage. Revista Verve, 29, 2016, p. 145-153.

SCHILLER, F. Sobre o sublime. In: SÜSSEKIND, Pedro (org.). Fredrich Schiller: do sublime ao trágico. Belo Horizonte: Autêntica, 2011.

VIANA, Allyson Bruno. Anarquismo em papel e tinta: imprensa, edição e cultura libertária (1945 - 1968). 2014. 441f. - Tese (Doutorado) - Universidade Federal do Ceará, Programa de Pós-graduação em História Social, Fortaleza (CE), 2014. 